\title{
The Production Economics of
}

\section{The Economics Production*}

\author{
YUSHAN HU \\ BEN G. LI \\ Boston College \\ Boston College
}

This draft: March 6, 2017

\begin{abstract}
The arrival of the internet age forces academic journals to adjust their output margins: journal length, article length, and number of published articles. Using data from 41 major economics journals spanning 21 years (1994-2014), we find that both journals and articles are getting longer, but the page share of an individual article within its journal is shrinking. This pattern is consistent with a monopolistic competition model that features within-firm (journal) specialization. As predicted by the model, the share of an individual article shrinks less in general-interest journals and better ranked journals, where expertise is less substitutable across topics. In this discipline that emphasizes the benefits of specialization, the expertise underpinning its publications is indeed divided in a specialized fashion.
\end{abstract}

JEL codes: A11, D43

Keywords: Division of labor, history of economics, academic publishing

${ }^{*}$ Corresponding author: Li (benli36@gmail.com), Assistant Professor, Department of Economics, Boston College, Chestnut Hill, MA, 02445. 


\section{Introduction}

Readers' willingness to pay for journals is declining. Discontinuing print journals is a current trend in academic libraries. Electronic journals are sold online, though their unit of sale is the article. This is anything but surprising. Currently, working papers become freely accessible online long before being published, and many final drafts remain freely accessible after being published. Journals are diminishing in their role as knowledge disseminators and instead are transitioning to a role as quality-controlled repositories of knowledge (Friberg, 2014; Zilibotti, 2014). ${ }^{1}$ An average page in a given journal receives less attention now than in the pre-internet era when researchers relied on journals to stay on the frontier of research advancements.

This study is concerned with how the annual outputs of journals, including their length and number of published articles, have evolved in the new age. Our data cover 41 prestigious economic journals, spanning two decades (1994-2014) that coincided with the time when the World Wide Web and online search engines revolutionized individual information intake. ${ }^{2}$ We find that both journal length and number of published articles have been steadily increasing, and more importantly, the page share of an average article within a journal has been decreasing. Think of every journal as a knowledge-making firm that charges consumers for every page of knowledge they read, journal length as its total output, and articles as its knowledge-making teams. The observed data pattern suggests that every team produces absolutely more but relatively less.

The observed data pattern is consistent with what an analogical within-firm specialization model predicts. As readers' attention on every published page declines, their willingness to pay reduces. In response, journals raise their outputs to compensate for the lost revenue. Suppose that introducing a team of experts (an article) incurs a fixed cost, and letting a few teams produce all the output overstretches their expertise. Then, as a tradeoff, every journal has an optimal number of teams (number of articles) every year, conditional on its annual output. When journals produce greater annual total outputs, the fixed costs of additional teams (articles) are economized. As a result, a greater number of articles are published, each being more focused on its core expertise. Therefore, both journal length and article number grow, with the latter margin growing more to reduce every article's output (page) share.

Up to this point, within-journal specialization is just one possible explanation. We next derive a unique prediction from it. Within a journal's scope, if the expertise is less substitutable across topics, the fixed costs of publishing more articles will be less economized, so that the page share of individual articles should decrease less. Conceivably, the expertise on one topic is more discounted on other topics (i) in general-interest journals than in field journals, and (ii) in journals with

\footnotetext{
${ }^{1}$ This phenomenon is also common in the sciences. For example, in mathematics and physics, nearly all papers are freely accessible through the arXiv repository (https://arxiv.org).

${ }^{2}$ In April 1993, the CERN (European Organization for Nuclear Research), where the World Wide Web was born, announced that the World Wide Web would be freely accessible to every internet user. Search engines were born later that year, including W3Catalog in September and Aliweb in November.
} 
stronger expertise overall. Thus, the page-share decrease should be less in general-interest journals and in better ranked journals. These hypotheses are found to be supported by the data, and our findings are robust to the use of different estimation methods, subsamples, and journal rankings.

Apart from type and ranking, there are two other journal characteristics that relate to the substitutability of expertise across topics within a journal. One is whether a journal imposes a page limit on initial submissions. We find the journals with such page limits highly conforming to our earlier hypotheses, while the patterns from the journals without page limits are weaker. This is consistent with the thesis of Card and DellaVigna (2014) on revealed preferences in submissions authors shorten their submissions following the imposed page limits if they have no better outlets that match their papers' qualities. A natural implication of their thesis is that journals would not impose page limits if the risk of having authors extend beyond their expertise is not a significant concern. In other words, for journals that impose page limits on initial submissions, submissions longer than the page limits overstretch the expertise that the journals believe those submissions to have.

The other journal characteristic that relates to the substitutability of expertise across topics is the degree of specialization of the researchers. In research fields that have more specialized researchers, the cross-topic expertise loss is expected to be less, so that the decrease in the page share of individual articles should be greater. In other words, letting more-specialized experts author articles in their fields runs a lower risk of overstretching expertise. We use the field-specific specialization index compiled by Ellison (2002a) and find evidence in support of our speculation.

The key mechanism of within-journal specialization is that journals, in a highly competitive environment, push articles to be short and focal. Dixit (1998) has an eloquent anecdote on this tendency:

As an editor of the Review of Economic Studies, (Frank) Hahn asked the author to cut down his paper from 40 pages to its essential core of three pages. When the author wrote a long and indignant letter, Hahn responded in two sentences: "Crick and Watson described the structure of DNA in three pages. Kindly explain why your idea deserves more space."

The analogy used by Frank Hahn may not be entirely appropriate, because the writing in economics, unlike that in hard sciences that build on lab experiments, usually needs more detailed descriptions, explanations and justifications. Nevertheless, his analogy exemplifies a key tradeoff in the business of academic publishing: a longer article is richer but easily strays from its central insights, and delivering more insights in fewer pages is the key to publishing a successful journal.

The first contribution of this paper is demonstrating the specialization patterns in the production of economic knowledge. Economics is a discipline about specialization and its own evolution exemplifies specialization. Starting as "an inquiry into the nature and causes of the wealth of nations" (Smith, 1776), economics has grown to be a modern social science that has 849 clusters 
of research topics (defined by JEL codes) and 1,953 journals (according to RePEc registrations). ${ }^{3}$ The 41 economics journals covered by our 21-year sample published 55,244 research articles. These articles specialized in distinct topics, which went far beyond the "nature and causes of the wealth of nations," and no modern economist can claim that she understands all of these articles even at a superficial level. Adam Smith referred to such a phenomenon as a division of labor.

There exist various approaches to formulating Adam Smith's division of labor, among which we chose Chaney and Ossa (2013) to guide our empirical study. ${ }^{4}$ Their approach, featuring monopolistic competition, introduces different teams, instead of pure labor, into the firms that make differentiated products. Launching more teams incurs more fixed costs, but letting teams specialize in certain parts of production reduces variable costs. This informs the importance of optimizing the structure of teams (essentially, expertise units) in the production of any expertise-intensive product. As teams become more specialized, they each contribute less output, but more teams are contributing at the same time and every team is becoming more productive. Think of a research project as a team that adds to the body of economic knowledge. We believe that most economists can agree with us on the increasing sophistication of economics papers, the narrowing breadth of research topics, and at the same time the remarkably rapid growth of modern economic knowledge.

This paper also sheds light on the operation of the economics profession. Economists have studied the whole production line in their own profession, from authorship (Hamermesh, 2013) and coauthorship (Laband and Tollison, 2000; Rosenblat and Mobius, 2004; Ray and Robson, 2016), to page limits on initial submissions (Card and DellaVigna, 2014), editing and refereeing (Brogaard, Engelberg, and Parsons, 2014; Cherkashin, Demidova, Imai, and Krishna, 2009; Welch, 2014), journal response time (Azar, 2007; Ellison, 2002a,b; Leslie, 2005), and citations (Einav and Yariv, 2006; Feenberg, Ganguli, Gaule, and Gruber, 2015; Huang, 2014; van Praag and van Praag, 2008). We consider such a thorough self-study of the profession not as a sign of the profession's narcissism, but as a deep inquiry into whether this profession, born for understanding and improving the efficiency of resource allocation, operates itself efficiently. ${ }^{5}$ Any deviation from economic efficiency in the profession reflects either a collective inadequacy in understanding efficiency, or a collective failure in correcting incentives. This being said, a careful self-study is always warranted.

Our paper departs from the existing introspection in two ways. First, we demonstrate the functional differences between general-interest journals and field journals. Having both types of journals, which is common in many sciences and social sciences, does not necessarily mean that different types of articles are published in them. General-interest journals could, as in some disciplines, publish high-quality articles, whether their topics are general or not. In that case, journal type is no different from journal ranking. Many economists feel that this is also the trend in eco-

\footnotetext{
${ }^{3}$ These statistics were accessed in January 2017.

${ }^{4}$ See Young (1928), Stigler (1951), Becker and Murphy (1992), and Yang (2001) for alternative approaches.

${ }^{5}$ Economists also study the business of other intellectuals, including mathematicians (Head, Li, and Minondox, 2015), scientists (Haeussler and Sauermann, 2016), lawyers (Garicano and Hubbard, 2003), and the academic publishing industry overall (Edlin and Rubinfeld, 2005; Jeon and Rochet, 2010; Nevo, Rubinfeld, and McCabe, 2005).
} 
nomics. At present, many articles in general-interest economic journals are as specialized as those in field journals, and whether their topics are general is oftentimes a subjective matter. In our study, general-interest journals turn out to be indeed unique. Our results show that conditional on journal rankings, the value of an average article in general-interest journals is more robust than its counterpart in field journals in this internet age. In other words, articles in general-interest journals are less substitutable with each other, not only intellectually but also in generating profits for the publishing business.

Second, we examine the journal length. Perhaps surprisingly, economists have rarely examined this direct measure of knowledge output. To our knowledge, the aforementioned Card and DellaVigna (2014) is the only exception that utilizes the information contained in publication length length of submissions in their setting. They note that, all else held equal, longer submissions are more likely to receive revise-and-resubmit verdicts and more citations afterwards, both suggesting a higher quality. Our paper is different from theirs in several important ways. One, their focus is on the impact of page limits, while ours is on the time trends in journal length and number of articles, and particularly the page shares of individual articles in their corresponding journals. In essence, we are interested in the relative length of publications while they are interested in absolute length and its determinants. Two, our study is about published articles rather than papers submitted to journals. Three, we inspect 41 quality journals (including the top ones) where most good papers written by most good economists are published.

The rest of the paper is organized as follows. In Section 2, we derive testable hypotheses from a stylized model of within-journal specialization. We describe our data in Section 3 and report our empirical results in Section 4. In Section 5, we conclude.

\section{Conceptual Framework and Estimating Equation}

In this section, we present a stylized model to guide our later empirical study. Our model, building on Chaney and Ossa (2013), follows a simple idea. As the attention paid by readers to an average published page declines, their willingness to pay for journals reduces, reducing the markups charged by journals. To compensate for the lost revenues, journals publish more pages and the additional pages are from both (1) additional articles and (2) additional pages per article. The former margin outgrows the latter, owing to within-journal specialization. As a result, the page share of an individual article shrinks. The page-share decrease is less in journals where expertise is less substitutable across topics. We specify the major regression at the end of the section, which will be estimated in Section 4. 


\subsection{Setup}

Readers "consume" $N$ economics journals. Readers have identical income and utility function: $U=\sum_{i=1}^{N} u\left(x_{i}\right)$, where $u\left(x_{i}\right)$ is the utility obtained from reading $x_{i}$ pages of journal $i . u\left(x_{i}\right)$ is differentiable, increasing, and concave in $x_{i}$. The elasticity of demand is $\epsilon\left(x_{i}\right)=\frac{-u^{\prime}\left(x_{i}\right)}{x_{i} u^{\prime \prime}\left(x_{i}\right)}$, where $\epsilon\left(x_{i}\right)>1$ and $\epsilon^{\prime}\left(x_{i}\right)<0$ for any $x_{i}>0$. In other words, the demand curves for $x_{i}$ are less convex than constant. Readers do not read all pages in a journal but selectively choose a fraction $1 / b$ to read. That is, if a journal has $y_{i}$ pages, $x_{i}=y_{i} / b$ pages are read by readers (different readers may choose different $x_{i}$ pages to read). $1 / b$ is a parameter that characterizes readers' attention. The smaller $1 / b$ is, the less attention is paid to the publication and thus the fewer pages are read.

Consider a representative journal, the subscript $i$ of which is omitted for convenience. It produces $y=\sum_{a=1}^{n} y(a)$ pages, where $y(a)$ is the length of article $a$, and $n$ is the number of articles published in the journal. We abstract away from cross-page differences within a journal. Specifically, all pages within an article are symmetric, and all articles in a journal are symmetric; therefore, all pages in a journal are symmetric. ${ }^{6}$

Two types of costs are incurred in the production of a journal. The first type is logistics costs, represented by $f$, incurred per article. They refer to the journal's own services devoted to every published article, including editing, refereeing, proofreading, typesetting, and printing services. ${ }^{7}$ The second type is expertise costs. Journals are written by authors using their expertise, and the expertise related to one research question does not fully carry over to another. We denote the scope of every journal by $[0,1]$, which is a continuum of (currently answered) research questions. Every published article addresses a core question and a few adjacent questions, and the adjacent questions farther from the core question incur a higher expertise cost per question. Formally, the expertise cost of a journal that consists of $n$ articles is $\int_{0}^{1 / n} z^{\gamma} d z$ per page, and the positive constant $\gamma$ specifies the growth rate of expertise cost on adjacent questions. When $n$ rises, the journal is written by a greater number of experts who focus more on their core expertise.

The above cost structure illustrates a clear tradeoff between article number and article length within a journal. A journal with $n=1$ has the lowest logistics costs, because all its pages are written by the same author(s) who covers the entire journal scope $[0,1]$. That would incur the highest expertise costs per page $\int_{0}^{1} z^{\gamma} d z$. To the contrary, a journal with a huge $n$ has extremely high publishing costs but very low expertise costs per page, because the journal is divided into numerous articles, each one written using the most relevant expertise. To strike a balance between the two polar cases, there exists an optimal number of articles conditional on any journal length $y$.

\footnotetext{
${ }^{6}$ In the data, within-journal variation in article length is quite small. The standard deviation of article length equals approximately a third of the average article length (mean: 0.32; median: 0.35).

${ }^{7}$ The costs of referring service include both the costs of referee management and referee expertise. The costs of referee management, such as the costs of searching, monitoring, and compensations paid to referees, are counted as logistics costs. The costs of referee expertise costs have been reflected in the expertise costs of published articles, since authors of published articles are typically chosen to be referees (i.e., the expertise in writing papers is also the expertise in referring papers.
} 
Formally, the total cost function of the journal production is

$$
C(y)=y \int_{0}^{1 / n} z^{\gamma} d z+n f,
$$

and the optimal article number is

$$
n=\left(\frac{y}{f}\right)^{\frac{1}{\gamma+2}}
$$

conditional on journal length $y$.

To determine journal length $y$, we integrate the above demand (reader) side and supply (journal) side in a market where journals compete monopolistically with each other. By equations (1) and (2), there is a free-entry (FE) condition under which price equals average total cost:

$$
p=\left(1+\frac{1}{\gamma+1}\right)\left(\frac{f}{y}\right)^{\frac{\gamma+1}{\gamma+2}}
$$

That is, given a market price $p$, journals that cannot publish every page with a cost lower than this level would not survive. At the same time, journals price their pages at the level

$$
p=\frac{1}{\gamma+1} \times \frac{\epsilon(x)}{\epsilon(x)-1}\left(\frac{f}{y}\right)^{\frac{\gamma+1}{\gamma+2}} .
$$

in order for profit-maximization (PM), where $\frac{\epsilon(x)}{\epsilon(x)-1}$ represents the journal's markup. Recall $x=$ $y / b$, so that the markup equals $\frac{\epsilon(y / b)}{\epsilon(y / b)-1}$. The above FE and PM schedules constitute a system whose equilibrium is denoted by $\left(p^{*}, y^{*}\right)$. We impose $\epsilon(0)>1+\frac{1}{\gamma+1}$ to ensure the existence and uniqueness of the equilibrium $\left(p^{*}, y^{*}\right)$.

By solving the FE-PM system, we obtain

$$
\epsilon\left(y^{*} / b\right)=1+\frac{1}{\gamma+1}
$$

where $y^{*}$ is endogenously determined. With $y^{*}$ solved, $x^{*}$ and $p^{*}$ are solvable, as are number of articles $n^{*}$ and number of journals $N^{*}$. Our later empirical analysis centers on journal length $y^{*}$, number of articles $n^{*}$, and most importantly, the length share of an article in its journal:

$$
S^{*} \equiv \frac{y^{*} / n^{*}}{y^{*}}=\frac{1}{n^{*}}=\left(\frac{f}{y^{*}}\right)^{\frac{1}{\gamma+2}} .
$$

From an empirical perspective, both $S^{*}$ and $n^{*}$ have the merit of being neutral to page styles and other such cross-journal differences. Notice that the variation in $S^{*}$ stems solely from $n^{*}$, but compared with $n^{*}, S^{*}$ has the additional merit that the original number of articles has been adjusted. For example, publishing 10 additional articles has different implications for a journal that initially published 20 articles per year compared to a journal that initially published 200 articles 
per year. $S^{*}$ captures that difference while $n^{*}$ does not. $^{8}$

\subsection{Different Journals}

We now link the growth rate of expertise cost $\gamma$ to the types and rankings of journals. Introducing heterogeneous costs into a monopolistic competition model usually renders the equilibrium number of firms $N_{i}$ and the composition of entrants indeterminable. However, our study tracks a highly stable selection of journals over time, so that changing journal number and composition are not a concern. Put differently, the following specifications and the resulting comparative statics are based on a given time-invariant equilibrium.

The parameter $\gamma$ is linked to journal type $\omega$ and ranking value $R$ :

$$
\gamma=\omega-\tau R
$$

where $\tau>0$ is a positive constant that fixes the importance of $R$ relative to $\omega$. With $R$ held equal, the $\gamma$ of general-interest $(G)$ journals is greater than that of field $(F)$ journals, or

$$
\omega_{G}>\omega_{F} .
$$

This is because general-interest journals publish articles that answer a larger variety of research questions than field journals, so that within the given scope $[0,1]$, the expertise associated with one question is less relevant to others in the journal. At the same time, with type $(\omega)$ held equal, in journals written using less expertise overall (i.e., weaker journals), the expertise related to one question attenuates less when applied to other questions. Note that a larger rank value $R$ means a weaker ranking: the journal ranked 10 th $(R=0.1)$ is weaker than the journal ranked 1 st $(R=0.01)$.

By inserting equation (5) into equation (3), one can immediately see that (1) given the same type, a weaker journal has a higher demand elasticity and thus a lower markup, and (2) given the same ranking, a field journal has a higher demand elasticity and thus a lower markup, in comparison with a general-interest journal.

\subsection{Hypotheses and Estimating Equation}

Hypotheses Now consider a marginal decline in $1 / b$, representing a decrease in the attention paid by readers to individual journal issues. What interest us is the resulting comparative statics. First and foremost, by equation (3), the marginal decline in $1 / b$ causes an increase in $y^{*} .{ }^{9}$ Intuitively, the decline in attention lowers the willingness to pay and thus markup, so that journals raise their

\footnotetext{
${ }^{8}$ That is because $d S^{*}=\frac{-1}{n^{* 2}} d n^{*} \neq \frac{1}{d n^{*}}$.

${ }^{9}$ The PM schedule may be either upward- or downward-sloping, which however both lead to an increase in $y^{*}$ in this setting.
} 
output (length) $y^{*}$ to compensate for lost revenues. When $y^{*}$ rises, the number of articles $n^{*}$ rises according to equation (2). That is, letting published articles be more specialized (i.e., answering fewer questions per article) helps to reduce the marginal cost per page. Recall that publishing more articles brings more fixed costs, which are however economized by the larger output $y^{*}$ here. As a net effect of a greater $y^{*}$ and a greater $n^{*}$, the page share of each article within the journal reduces. Formally,

$$
\frac{d S^{*}}{d\left(\frac{1}{b}\right)}=\underbrace{\frac{d S^{*}}{d y^{*}}}_{<0} \underbrace{\frac{d y^{*}}{d\left(\frac{1}{b}\right)}}_{<0}>0 .
$$

The rising $y^{*}$, rising $n^{*}$, and declining $S^{*}$ are the first sets of predictions that we will test using our data.

In our later empirical study, we will use a time-trend variable to proxy for the declining $1 / b$. Although the declining attention accords with our experience as readers, the time-trend variable inevitably captures other trends in the publishing industry. Therefore, our major specification has to count on at least one other variation that can identify the trend specific to the declining $1 / b$. This is why the types and rankings of journals are introduced:

$$
\left|\frac{d S^{*}}{d y^{*}}\right|_{G}<\left|\frac{d S^{*}}{d y^{*}}\right|_{F},
$$

and

$$
\frac{d^{2} S^{*}}{d y^{*} d R}>0
$$

where the inequalities follow from equations (4) and (5). Notice that the second term in inequality (7), namely $\frac{d y^{*}}{d(1 / b)}$, does not vary with journal type or journal ranking. Inequalities (8) and (9) lead to the major hypotheses that will be tested:

Hypotheses. In response to a negative attention shock $d(1 / b)<0, S^{*}$ shrinks less (i) in generalinterest journals than in field journals, and (ii) in journals that have a better ranking (i.e., a smaller $R)$.

The intuition behind the hypotheses are as follows. A journal with less substitutable expertise across its topics - either because it is a general-interest journal or it has stronger expertise on all its topics - will find publishing more articles less useful in curtailing costs. In other words, facing the same $f$ per article, soliciting more articles is less economical for journals with a higher $\gamma$. For them, the number of published articles may still rise, but to a lesser degree. 
Estimating Equation Hereafter, we omit the asterisk in superscripts for convenience. The above hypotheses inform a difference-in-differences regression:

$$
S=\beta \cdot(-1 / b)+\bar{\theta} \cdot\left[\begin{array}{l}
G \\
R
\end{array}\right]+\bar{\delta} \cdot(-1 / b) \cdot\left[\begin{array}{l}
G \\
R
\end{array}\right]+v,
$$

where $G$ is a general-interest dummy, $R$ is rank value, $-1 / b$ represents the aforementioned declining attention, and $v$ is the error term. As noted earlier, we use a time-trend variable to proxy for the decreasing attention $-1 / b$. Denote the time-trend variable by $T_{t}$, then a full-fledged regression follows:

$$
S_{i t}=\beta \cdot T_{t}+\bar{\theta} \cdot\left[\begin{array}{c}
G_{i} \\
R_{i}
\end{array}\right]+\bar{\delta} \cdot T_{t} \cdot\left[\begin{array}{c}
G_{i} \\
R_{i}
\end{array}\right]+\xi^{\prime} X_{i t}+v_{i t},
$$

where $i$ indexes journal, $t$ indexes year, and $X_{i t}$ represents control variables. In particular, the fixed cost (per article) parameter $f$ will be proxied for using the submission fees of journals. Our major hypotheses pertain to the estimated coefficients of interaction terms: $\hat{\bar{\delta}}=\left[\hat{\delta}_{G}>0, \hat{\delta}_{R}<0\right]^{\prime}$.

The rest of the regression (10) is not our major interest but is still noteworthy. First, the coefficient of the pure time trend $\beta$ is not identifiable. The marginal effect of the time-trend variable $T_{t}$ on $S_{i t}$ is

$$
\frac{\partial S_{i t}}{\partial T_{t}}=\beta+\delta_{G} G_{i}+\delta_{R} R_{i}
$$

The coefficient of the field-journal indicator $\left(G_{i}=0\right)$ and the coefficient of the best journal are mixed with the pure time trend $\beta$ (i.e., effect of declining attention $-1 / b$ ), rendering none of the three separately identifiable.

Second, the coefficients of the non-interacted $G_{i}$ and $R_{i}$, namely $\hat{\theta}_{G}$ and $\hat{\theta}_{R}$, are interesting but are not our focus. Equations (3) and (5) suggest that general-interest journals and better ranked journals have a smaller $S_{i t}$ :

$$
\hat{\theta}_{G}<0, \hat{\theta}_{R}>0
$$

which are actually supported by our empirical results. However, such coefficients also capture other cross-sectional differences between journals that have different types and rankings. We caution against interpreting them as evidence of our model, and focus our study instead on the interaction terms.

Third, one may wonder if the effect of $R$ on $\gamma$ differs between general-interest journals and field journals. When such a difference exists, the previous equation (5) has a more general form:

$$
\gamma=\omega-\tau_{\omega} R
$$

where the slope of $R$, now denoted by $\tau_{\omega}$, differs between general-interest and field journals. To investigate whether $\tau_{\omega}$ is journal-type specific, we will experiment with introducing a triple difference term $T_{t} \cdot G_{i} \cdot R_{i}$ into regression (11). Its estimated coefficient will be unequal to zero if $\tau$ varies 
by journal type.

Lastly, the error term $v_{i t}$ will be clustered, following the method of Cameron, Gelbach, and Miller (2011), to allow arbitrary clustering along the $i$ and $t$ dimensions. This addresses both the within-journal autocorrelation, within-year correlation, and a combination of the two in the error term.

We next move on to describe our data and some basic data patterns of $y_{i t}, n_{i t}$ and $S_{i t}$.

\section{Data}

\section{$3.1 \quad$ Sources}

Our primary data source is the tables of contents (TOCs) of journals. Through web scraping, we obtained the TOCs of 41 economics journals during the 1994-2014 period. A list of the journals and their available years are provided in Table A1. The four newest journals have a few missing years because they did not exist during that entire time span. Overall, the pool of journals is highly stable over time. We excluded published entries in journals that do not make original contributions, such as editorials, award announcements, minutes, and addenda. ${ }^{10}$ After cleaning, our dataset contains TOC information for 55,244 published articles.

The selection of the 41 journals was based on two major considerations. The first is their reputations in the economics profession. We use the union set of three journal classifications as the range of journal candidates: (1) the top-30 journals in the RePEc aggregate rankings, (2) the A+, A and B journals in the Kiel Institute's journal list, and (3) the journals classified by Engemann and Wall (2009) as where "ambitious economists" publish. These three classifications are widely perceived to be objective, and offer different perspectives on evaluating journals. The former two classifications also provide the ranking values that will be used in our later regression analysis. ${ }^{11}$ Between the two rankings, the RePEc rankings are our primary measure of $R$ because their values are numeric and continuous, while the Kiel Institute's rankings have only three discrete ratings. ${ }^{12}$ The second consideration is the scrapablity of their TOCs. Not all journals make all of their online TOCs publicly available. There are journal websites that purposely hide their TOC information from open web access. Such journal candidates are excluded from our dataset.

The discipline of economics in this study is broadly defined to include finance, marketing, and

\footnotetext{
${ }^{10}$ See the Appendix for details.

${ }^{11}$ The classifications compiled in Engemann and Wall (2009) are located in Table 3. The RePEc journal rankings can be found at https://ideas.repec.org/top/top.journals.all.html, while the Kiel institute's rankings can be found at https://www.ifw-kiel.de/forschung/internal-journal-ranking. Notice that both rankings change over time. The ranking values that we use were accessed in July 2015.

${ }^{12}$ All journal rankings are controversial to some extent, having their own strengths and weaknesses. This is because journal rankings rely on the ranking methods in use, which inevitably involve judgments made by the researchers who compile the rankings.
} 
accounting. Economists in these three fields are typically affiliated with business schools (b-schools) of universities. They receive training similar to (sometimes the same as) economists affiliated with economics departments. In the economics profession, there is neither a clear division between economics-department economists and b-school economists, nor a strict criterion to designate a research paper as an economics-department paper as opposed to a b-school paper. ${ }^{13}$ We have no intention to create such divisions among economists and their works. However, journals in those fields do share some characteristics that distinguish them from other economics journals, such as higher submission fees, a relatively smaller audience, and being house journals of professional associations separate from economic associations. Therefore, we refer to them as "b-school journals," as opposed to other economics journals (which are referred to as "pure economics journals"). This distinction is used mainly in robustness checks to determine whether there exist potential differences between the two groups of journals.

\section{$3.2 \quad$ Variables}

The descriptive statistics of our working dataset are reported in Table 1, where most variables are self-explanatory. Below, we elaborate on a few variables. One is the number of pages, which is our measure of journal length. It is a simple count of pages provided in the TOCs of journals. In Figure 1, we plot the number of pages of every journal against time (the 21 years). Among the 42 plots, the first is concerned with the total pages of all the 41 journals and each of the following 41 plots corresponds to one single journal. The total of all journals has a significantly upward trend, which is also the case for most journals during the two decades.

Despite the revealing patterns, we should be aware that the number of pages is not comparable across journals. The incomparability results from two factors. First, journals use different page styles (e.g., typeface, font size, line space, and page margin), such that one page in a journal is not an equivalent of one page in another. ${ }^{14}$ Second and more subtly, theoretical/empirical inclination often influences the length of articles and thus journals. Empirical articles are typically longer because data charts and tables take larger amounts of space than text. Moreover, some journals encourage putting detailed proofs in appendices (usually having smaller fonts and narrower line spaces) or require detailed proofs be provided as online appendices that are not published in the journals. This may make theoretical articles even shorter. Of course, the opposite may also happen. If a journal requires additional tables and data charts to be put in online appendices but keeps full-fledged proofs in the text, its empirical articles would be shorter than theoretical ones. In sum, articles and journals, even typesetted using the same page style, may still be incomparable

\footnotetext{
${ }^{13}$ In the US higher education system, the majority of academic economists are affiliated with economics departments, and the majority of economics departments are part of arts and sciences schools (colleges).

${ }^{14}$ Card and DellaVigna (2014) nicely addressed this type of incomparability by extracting word counts from the pdf files of original submissions. We are unable to extract word counts in many journals because their articles published in the 1990s were converted into pdf files as scanned images rather than using word-processing software. Using images as source files makes word-counting infeasible (current OCR technologies are not helpful in this case).
} 


\begin{tabular}{lccc}
\hline \hline Overview & & \\
Number of years & & $9-21$ ฯ \\
Number of papers & & 55244 \\
Number of journals & & 41 \\
Number of publishers & & 13 \\
& & & \\
\hline Descriptive statistics ${ }^{*}$ & $\mathrm{~N}$ & Mean & St.D \\
& & & \\
At the journal-year duplet level & & & \\
Number of papers & 831 & 66.48 & 44.67 \\
Number of pages & 831 & 1368.56 & 803.59 \\
Number of pages per paper & 831 & 22.28 & 6.99 \\
Page share of an average paper & 831 & 0.02 & 0.01 \\
Time index A & 831 & 10.18 & 6.04 \\
Time index B & 831 & 4.06 & 2.00 \\
Time index C & 831 & 2.02 & 0.82 \\
& & & \\
At the journal level & & & \\
Ranking value\# & 41 & 0.21 & 0.20 \\
Pure-economics journal dummy & 41 & 0.88 & 0.33 \\
Top-5 journal dummy & 41 & 0.12 & 0.33 \\
Page limit (on initial submissions) dummy & 41 & 0.32 & 0.47 \\
Submission fee (unit 100 US dollars)§ & 41 & 0.87 & 1.12 \\
General-interest journal dummy & 0.32 & 0.47 \\
Ellison specialization index $\triangle$ & 0.27 & 0.11 \\
\hline \hline
\end{tabular}

Notes: * Further details can be found in the text. I Most journals have 21 years.

Details of the journals and their year spans can be found in Table A1. \# It refers to the RePEc rankings. § The only other currency used in submission fee payments is euros, and 100 euro=112 US dollars is used in conversion. $\triangle$ The index is from Table 9 in Ellison (2002a).

in length. Therefore, as discussed in Section 2, our major interest is in $S_{i t}$, namely the page share of an average article within its journal-year duplet. Unlike journal and article length, the pageshare variable $S_{i t}$ has automatically adjusted for cross-journal differences in both page styles and theoretical/empirical inclination.

It is important to note that some journals (e.g., those published by Elsevier) switched to a more compact page style during the sample period. By using a more compact page style, a journal can squeeze in more articles per year, which tends to raise the number of articles published per 
year and thus reduces the page shares of individual articles. Such changes make $S_{i t}$ of journal $i$ not comparable with itself over time. However, the page-style changes are, by themselves, in line with what our model predicts - the denser text fits more articles in journal issues. Therefore, it is not an empirical concern in our later empirical analysis, even though it might cause the uptrend of journal length in Figure 1 to be understated.

Also noteworthy are the time-trend variables that we constructed. Remember that the timetrend variable is used to proxy for the declining attention of readers. A more rigid trend variable (e.g., incremental by one every seven years rather than every year) is more likely to secure a solid trend, but meanwhile has less variation for econometric use. To strike a balance between the two considerations, we constructed three different trend variables, hereafter referred to as time indexes A, B and C. Time index A starts from 0 and increases by one every calendar year, while Time indexes $\mathrm{B}$ and $\mathrm{C}$ increase every three years and seven years, respectively.

There were 13 publishers involved in the production of the 41 journals during the sample period. ${ }^{15}$ In our later regression analysis, we always include publisher fixed effects (or journal fixed effects if applicable, which are stricter than publisher fixed effects). Notice that some journals in the sample changed publishers during the sample period. We use their latest publishers to construct those fixed effects. However, using their previous publishers does not alter our findings. ${ }^{16}$

We found the information on submission fees (if applicable) from journals' guidelines for authors. The original fees were in either US dollars or euros, and we converted fees in euros to US dollars using the exchange rate 100 euros=112 dollars. Lastly, Table 1 also mentions the page limits on initial submissions and the Ellison specialization index. We will explain them in detail when they are used (see Section 4.3).

\footnotetext{
${ }^{15}$ The American Economic Association (AEA), the American Finance Association (AFA), and the European Economic Association (EEA) publish their house journals independently, while other house journals are officially published by commercial publishers. In our sample, the American Economic Review (AER) and the American Economic Journal: Applied Economics are published by the AEA. The Journal of Finance is published by the AFA. The Journal of the European Economic Association (JEEA) is published by the EEA.

${ }^{16}$ Acquisitions of publishers suggest reduced price margins, revenues, and profits of the acquired publishers. This is consistent with the outcome of readers' declining attention and willingness to pay in our model.
} 


\section{Figure 1: Total Page Length of Economics Journals}
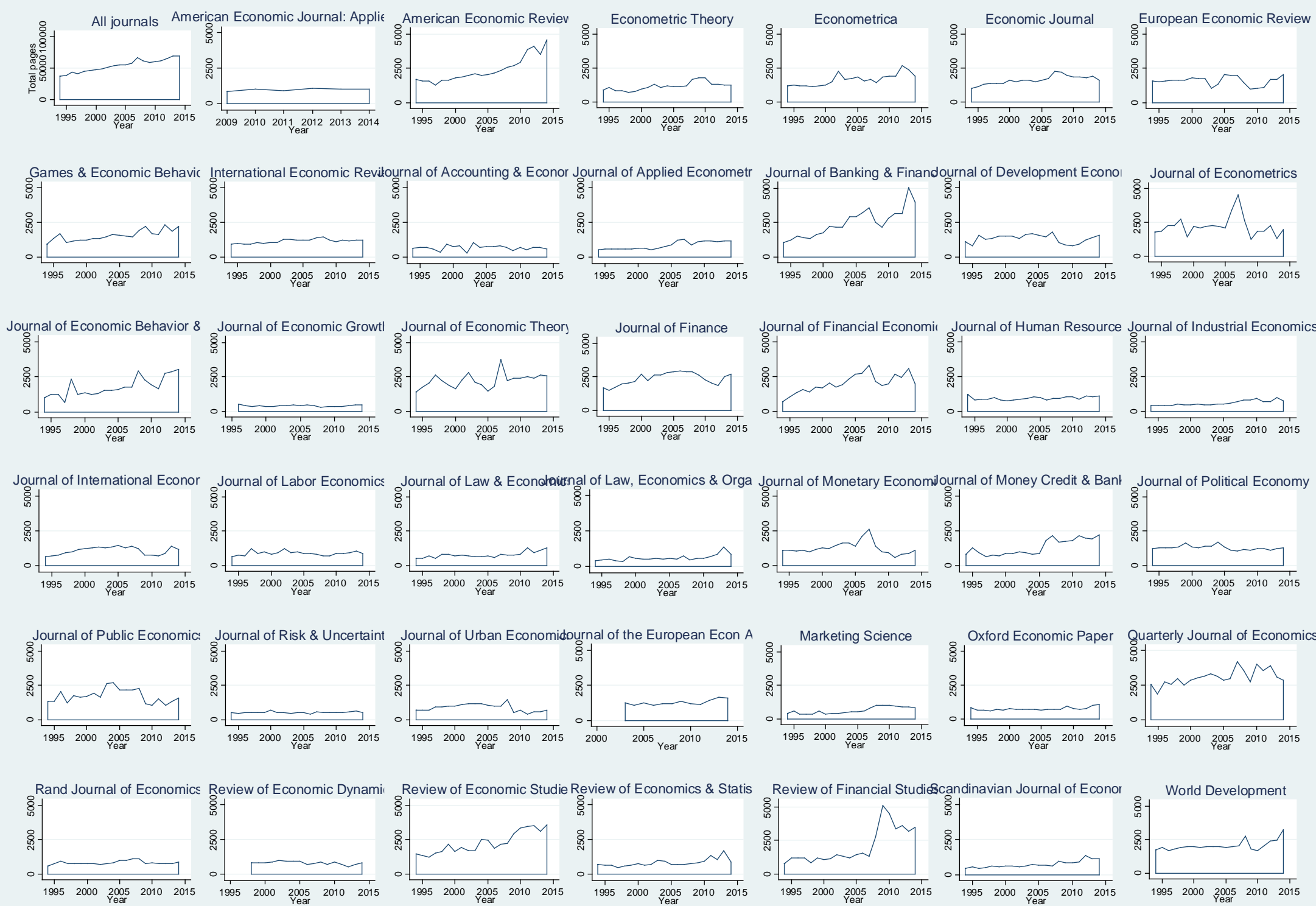


\subsection{The Flourishing Economics}

In the rest of this section, we investigate how the economic publications in our sample grew during the 21-year period. This investigation is motivated by two considerations. First, knowing the basic time patterns of the publications in our sample is meaningful in its own right, as they represent most of the new economic knowledge produced in the last two decades. Second and more importantly, this exercise illustrates whether the model we described in Section 2 is appropriate for rationalizing recent economic knowledge production. The model predicts longer journal $y_{i t}$, more articles $n_{i t}$, and shrinking page share per article $S_{i t}$. If these patterns are refuted by the data, a different model should be sought and thus there would be no point to test the hypotheses derived from the model.

In Table 2, three margins of the economic publications are regressed on each of the three time indexes. We use the most stringent fixed effects - journal fixed effects - in all columns. As mentioned earlier, following the method of Cameron et al. (2011), we cluster the error term $v_{i t}$ in equation (11) and allow arbitrary clustering along the $i$ and $t$ dimensions. This addresses both the within-journal autocorrelation and within-year correlation in the error term.

A positive and statistically significant time trend is found in journal length $\left(y_{i t}\right)$ and number of articles $\left(n_{i t}\right)$ under all specifications. An average journal publishes 35.65 more pages and 1.61 more articles every year. Notice that the 35.65 pages here are based on an "average page style," so that the magnitude should not be taken literally. ${ }^{17}$ As a net effect of the two, the page share of an average article $S_{i t}$ decreases by approximately 0.03 percentage point per year, which means about a half percentage point decrease over a 21-year period. Recall that in Table 1, an average article in an average journal-year accounts for two percent (two percentage points) of its total pages, with one percent (one percentage point) being the corresponding standard deviation. So, a half-percentage-point decrease is a substantial decrease. It is important to notice that if there were an ongoing fashion of writing shorter articles, that could also generate a shrinking $S_{i t}$, but that would not demonstrate longer or more articles as Table 2 does.

In Table 3, we compare the three margins across journal groups. Panel A demonstrates a comparison between high-ranking journals and low-ranking journals, and Panel B between pureeconomics journals and b-school journals. Since both ranking-related variables and the pureeconomics/b-school dummy are time-invariant journal characteristics, we cannot use journal fixed effects here. Instead, we include (1) publisher fixed effects, which control for market powers and other publisher differences and (2) year fixed effects, which control for time-varying differences (including time trend). Not using journal fixed effects also enables us to include submission fees as a control variable in our regressions.

Panel A of Table 3 shows that top-5 journals (the American Economic Review, the Econometrica, the Journal of Political Economy, the Quarterly Journal of Economics, and the Review

\footnotetext{
${ }^{17}$ Strictly speaking, the estimated 35.65 pages are based on an averagely styled page of the best field journal(s) (recall equation (12)).
} 
Table 2: Growth in Economics Publications along Different Margins

\begin{tabular}{|c|c|c|c|c|c|c|c|c|c|}
\hline & $(1)$ & $(2)$ & $(3)$ & $(4)$ & (5) & $(6)$ & $(7)$ & (8) & $(9)$ \\
\hline Dep. Variable: & \multicolumn{3}{|c|}{ Total pages published in a year } & \multicolumn{3}{|c|}{ Number of papers published in a year } & \multicolumn{3}{|c|}{$\begin{array}{c}\text { Average page share within journal-year } \\
\text { duplets }\end{array}$} \\
\hline Time index A & $\begin{array}{c}35.65^{* * *} \\
(7.606)\end{array}$ & & & $\begin{array}{c}1.612^{* * *} \\
(0.473)\end{array}$ & & & $\begin{array}{c}-0.000262^{* * *} \\
(0.000101)\end{array}$ & & \\
\hline Time index B & \multicolumn{3}{|c|}{$\begin{array}{c}106.3^{* * *} \\
(22.51)\end{array}$} & \multicolumn{3}{|c|}{$\begin{array}{c}4.839^{* * *} \\
(1.389)\end{array}$} & \multicolumn{3}{|c|}{$\begin{array}{c}-0.000782^{* * *} \\
(0.000297)\end{array}$} \\
\hline Time index $\mathrm{C}$ & & & $\begin{array}{c}239.8^{* * *} \\
(60.26) \\
\end{array}$ & & & $\begin{array}{c}11.57^{* * *} \\
(3.317)\end{array}$ & & & $\begin{array}{r}-0.00187^{* * *} \\
(0.000715) \\
\end{array}$ \\
\hline Journal fixed effects & $\mathrm{Y}$ & $\mathrm{Y}$ & $\mathrm{Y}$ & $\mathrm{Y}$ & $\mathrm{Y}$ & $\mathrm{Y}$ & $\mathrm{Y}$ & $\mathrm{Y}$ & $\mathrm{Y}$ \\
\hline Observations & 831 & 831 & 831 & 831 & 831 & 831 & 831 & 831 & 831 \\
\hline R-squared & 0.744 & 0.742 & 0.731 & 0.760 & 0.760 & 0.758 & 0.855 & 0.855 & 0.854 \\
\hline
\end{tabular}

of Economic Studies) publish longer and more articles, and every article in them accounts for a smaller share of the journal length every year. In fact, not only the top journals, but better ranked journals overall, publish longer and more articles, with each article accounting for less. This is consistent with what our model implies (see inequalities (13)).

Panel B of Table 3 compares the aforementioned pure-economics journals with b-school journals. Overall, pure-economics journals publish longer and more articles than b-school journals, though there is no significant difference in page share $S_{i t}$ between the two groups. The last three columns in Panel B control for ranking values, which results in a decrease in the differences in journal length and number of articles between the two groups. Interestingly, in both panels, the submission fee has negative coefficients in the regressions of total pages and number of articles, and positive signs in the regressions of page shares. This is consistent with our model's implications: a higher submission fee suggests a higher fixed cost $f$, which reduces the number of articles and raises the page share of an average article (see equations (2) and (4)). ${ }^{18}$

With the overall patterns confirmed, we now move on to the main body of our empirical study that focuses on the share variable $S_{i t}$.

\section{Empirical Results}

\subsection{Main Findings}

We now run regression (11) using the data described in Section 3. Our main results are reported in Table 4. We use each of the three time indexes and control for submission fees. Since journal

\footnotetext{
${ }^{18}$ Our model does not predict an effect of $f$ on $y$, which however can be rationalized as a supply-side effect in the background. That is, a high submission fee charged by a journal discourages all potential authors from publishing papers in that journal. This supply-side effect may reduce journal length $y$.
} 
Table 3: Margins of Different Journal Groups

\begin{tabular}{|c|c|c|c|c|c|c|}
\hline Dep. Variable: & $\begin{array}{c}\text { Total pages } \\
\text { published in } \\
\text { a year }\end{array}$ & $\begin{array}{c}\text { Number of } \\
\text { papers } \\
\text { published in } \\
\text { a year }\end{array}$ & $\begin{array}{c}\text { Average page } \\
\text { share within } \\
\text { journal-year } \\
\text { duplets }\end{array}$ & $\begin{array}{c}\text { Total pages } \\
\text { published in } \\
\text { a year }\end{array}$ & $\begin{array}{l}\text { Number of } \\
\text { papers } \\
\text { published in } \\
\text { a year }\end{array}$ & $\begin{array}{l}\text { Average page } \\
\text { share within } \\
\text { journal-year } \\
\text { duplets }\end{array}$ \\
\hline \multicolumn{7}{|c|}{ Panel A: Different quality groups } \\
\hline & $(1)$ & $(2)$ & $(3)$ & $(4)$ & $(5)$ & $(6)$ \\
\hline Top-5 journal dummy & $\begin{array}{c}1,353^{* * *} \\
(259.3)\end{array}$ & $\begin{array}{c}52.00^{* * *} \\
(14.91)\end{array}$ & $\begin{array}{c}-0.0156^{* * *} \\
(0.00272)\end{array}$ & & & \\
\hline Ranking value§ & & & & $\begin{array}{c}-2,996^{* * *} \\
(376.4) \\
\end{array}$ & $\begin{array}{c}-86.37^{* * *} \\
(18.30) \\
\end{array}$ & $\begin{array}{c}0.0280^{* * *} \\
(0.00629) \\
\end{array}$ \\
\hline Fee & $\begin{array}{c}-467.0^{* * *} \\
(147.5) \\
\end{array}$ & $\begin{array}{c}-25.93^{* * *} \\
(8.861) \\
\end{array}$ & $\begin{array}{c}0.00898^{* * *} \\
(0.00248) \\
\end{array}$ & $\begin{array}{c}-439.3^{* * *} \\
(82.26) \\
\end{array}$ & $\begin{array}{c}23.86^{* * *} \\
(7.435) \\
\end{array}$ & $\begin{array}{c}0.00843^{* * *} \\
(0.00187)\end{array}$ \\
\hline Year fixed effects & $\mathrm{Y}$ & $\mathrm{Y}$ & $\mathrm{Y}$ & $\mathrm{Y}$ & $\mathrm{Y}$ & $\mathrm{Y}$ \\
\hline Publisher fixed effects & $\mathrm{Y}$ & $\mathrm{Y}$ & $\mathrm{Y}$ & $\mathrm{Y}$ & $\mathrm{Y}$ & $\mathrm{Y}$ \\
\hline Observations & 814 & 814 & 814 & 814 & 814 & 814 \\
\hline R-squared & 0.596 & 0.578 & 0.708 & 0.631 & 0.558 & 0.696 \\
\hline \multicolumn{7}{|c|}{ Panel B: Different affiliation groups } \\
\hline & $(7)$ & $(8)$ & $(9)$ & $(10)$ & $(11)$ & $(12)$ \\
\hline Pure-economics journal dummy & $\begin{array}{l}877.6^{* *} \\
(409.0)\end{array}$ & $\begin{array}{c}90.74^{* * *} \\
(15.19)\end{array}$ & $\begin{array}{c}-0.0119 \\
(0.00767)\end{array}$ & $\begin{array}{l}349.0^{* *} \\
(176.0)\end{array}$ & $\begin{array}{c}70.28^{* * *} \\
(10.62)\end{array}$ & $\begin{array}{l}0.000719 \\
(0.00474)\end{array}$ \\
\hline Ranking value§ & & & & $\begin{array}{c}-2,984^{* * *} \\
(371.1) \\
\end{array}$ & $\begin{array}{c}-83.90^{* * *} \\
(14.63) \\
\end{array}$ & $\begin{array}{c}0.0280^{* * *} \\
(0.00630) \\
\end{array}$ \\
\hline Fee & & & & $\begin{array}{c}-393.4^{* * *} \\
(98.03) \\
\end{array}$ & $\begin{array}{c}-14.60^{* * *} \\
(5.444) \\
\end{array}$ & $\begin{array}{c}0.00853^{* * *} \\
(0.00237) \\
\end{array}$ \\
\hline Year fixed effects & $\mathrm{Y}$ & $\mathrm{Y}$ & $\mathrm{Y}$ & $\mathrm{Y}$ & $\mathrm{Y}$ & $\mathrm{Y}$ \\
\hline Publisher fixed effects & $\mathrm{Y}$ & $\mathrm{Y}$ & $\mathrm{Y}$ & $\mathrm{Y}$ & $\mathrm{Y}$ & $\mathrm{Y}$ \\
\hline Observations & 814 & 814 & 814 & 814 & 814 & 814 \\
\hline R-squared & 0.438 & 0.538 & 0.595 & 0.634 & 0.595 & 0.696 \\
\hline
\end{tabular}

§ A larger ranking value means a weaker ranking. Standard errors are reported in parentheses, allowing for arbitrary clustering across journals and years. $* * * \mathrm{p}<0.01,{ }^{* *} \mathrm{p}<0.05,{ }^{*} \mathrm{p}<0.1$.

type $G_{i}$ and ranking value $R_{i}$ are time-invariant, journal fixed effects cannot be used here. Instead, publisher fixed effects are included in all regressions. We start with a specification that excludes the interaction term. Its results are reported in column (1), where the page share of an average article turns out to be smaller in general-interest journals and better ranked journals. This is consistent with our theory (recall inequalities (13)), though such a cross-sectional comparison is not our main interest, as noted earlier. The page share shrinks over time, as revealed by the negative and statistically significant coefficient of the time index. ${ }^{19}$

More important findings are presented in columns (2)-(4), where the interaction terms are

\footnotetext{
${ }^{19}$ Notice that the pure time trend, the coefficient of $G_{i}=0$, and the coefficient of the smallest $R_{i}$ cannot be separately identified (recall equation (12)). This being said, the $\hat{\delta}_{G}=0.000377$ should not be interpreted as a growing page share.
} 
Table 4: Page Share within Journal-Year Duplets

\begin{tabular}{|c|c|c|c|c|}
\hline & (1) & $(2)$ & $(3)$ & (4) \\
\hline \multicolumn{5}{|c|}{ Dep. Variable: average page share within journal-year duplets } \\
\hline \multirow[t]{2}{*}{ General interests dummy } & $-0.00785^{* * *}$ & $-0.0116^{* * *}$ & $-0.0123^{* * *}$ & $-0.0133^{* * *}$ \\
\hline & $(0.00299)$ & $(0.00287)$ & $(0.00299)$ & $(0.00302)$ \\
\hline \multirow[t]{2}{*}{ Ranking value§ } & $0.0199^{*}$ & $0.0295^{* * *}$ & $0.0315^{* * *}$ & $0.0348^{* * *}$ \\
\hline & $(0.0106)$ & $(0.0107)$ & $(0.0109)$ & $(0.0110)$ \\
\hline \multirow[t]{2}{*}{ Time index A } & $-0.000206^{* *}$ & -0.000110 & & \\
\hline & $(8.80 \mathrm{e}-05)$ & $(0.000173)$ & & \\
\hline \multirow[t]{2}{*}{ Time index A $\times$ General-interest dummy } & & $0.000377^{* *}$ & & \\
\hline & & $(0.000160)$ & & \\
\hline \multirow[t]{2}{*}{ Time index A $\times$ Ranking value } & & $-0.000963^{* *}$ & & \\
\hline & & $(0.000480)$ & & \\
\hline \multirow[t]{2}{*}{ Time index B } & & & -0.000322 & \\
\hline & & & $(0.000488)$ & \\
\hline \multirow[t]{2}{*}{ Time index B $\times$ General-interest dummy } & & & $0.00112^{* *}$ & \\
\hline & & & $(0.000466)$ & \\
\hline \multirow[t]{2}{*}{ Time index $\mathrm{B} \times$ Ranking value } & & & $-0.00290 * *$ & \\
\hline & & & $(0.00134)$ & \\
\hline \multirow[t]{2}{*}{ Time index $\mathrm{C}$} & & & & -0.000705 \\
\hline & & & & $(0.00113)$ \\
\hline \multirow[t]{2}{*}{ Time index $\mathrm{C} \times$ General-interest dummy } & & & & $0.00274^{* * *}$ \\
\hline & & & & $(0.00105)$ \\
\hline \multirow[t]{2}{*}{ Time index $\mathrm{C} \times$ Ranking value } & & & & $-0.00744^{* *}$ \\
\hline & & & & $(0.00297)$ \\
\hline \multirow[t]{2}{*}{ Fee } & 0.00208 & 0.00207 & 0.00207 & 0.00208 \\
\hline & $(0.00143)$ & $(0.00144)$ & $(0.00143)$ & $(0.00143)$ \\
\hline Publisher fixed effects & $\mathrm{Y}$ & $\mathrm{Y}$ & $\mathrm{Y}$ & $\bar{Y}$ \\
\hline Observations & 831 & 831 & 831 & 831 \\
\hline R-squared & 0.578 & 0.593 & 0.592 & 0.593 \\
\hline
\end{tabular}

included and each column uses a different time index. The estimated coefficients of the interaction terms are in line with our major hypotheses: $\hat{\delta}_{G}>0, \hat{\delta}_{R}<0$. That is, the page share of an average article shrinks less per year in general-interest journals and better ranked journals. This holds in all three columns. The coefficients of submission fee are statistically insignificant in these columns.

In Table 5, we experiment with the three-way interaction $T_{t} \cdot G_{i} \cdot R_{i}$ mentioned earlier. We insert it into regression (11) to identify whether the role of journal ranking differs between generalinterest journals and field journals in determining the trend in $S_{i t}$. The regression is otherwise the same as the original regression (11). The three-way interaction term is added as the last regressor (labeled "IV.A/B/C") in all columns. It is not significantly different from zero, regardless of the specification in use, indicating that the role of journal ranking in determining the trend is not 
Table 5: Difference-In-Difference-In-Differences Estimates

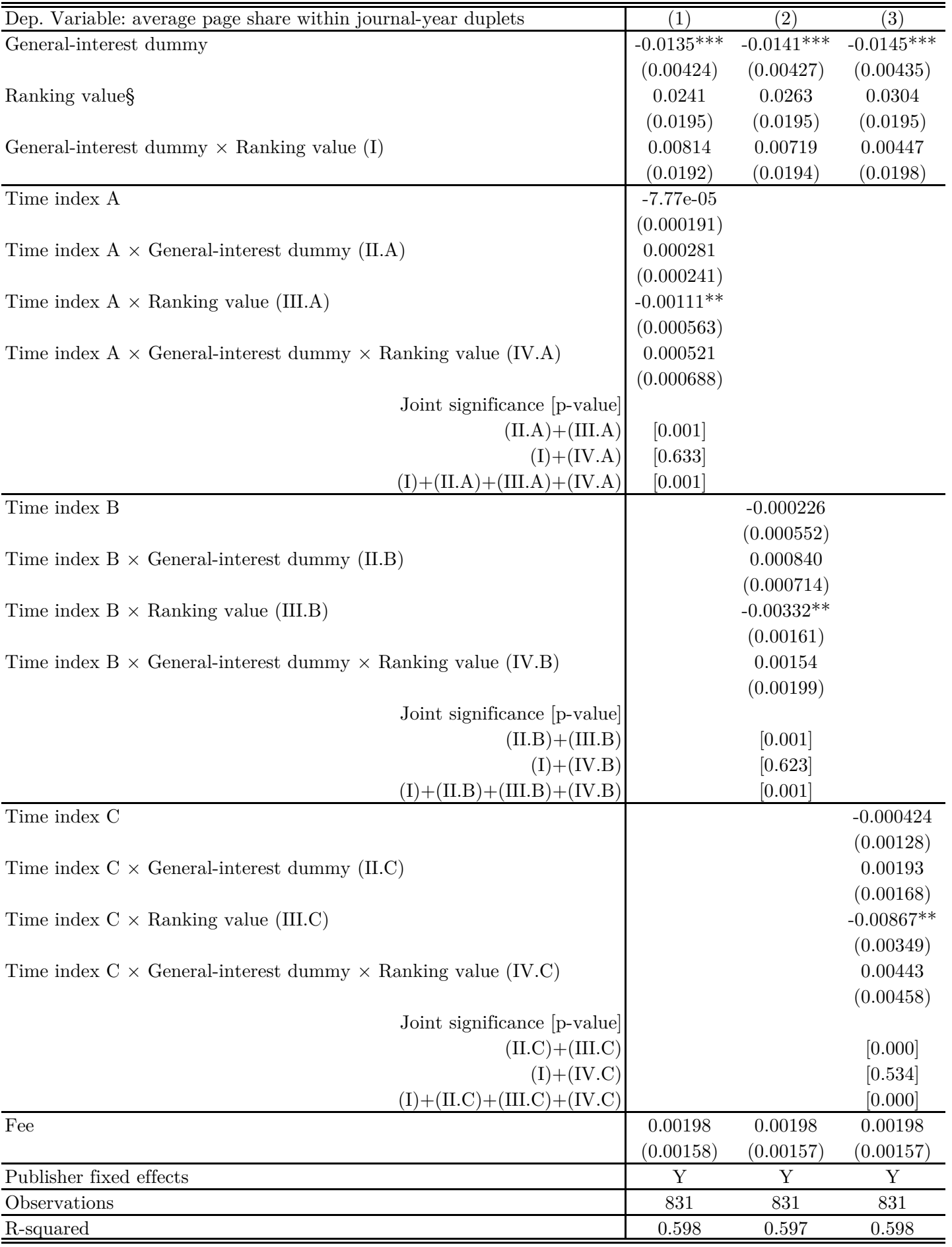

§ A larger ranking value means a weaker ranking. The ".A" denotes that the time index $\mathrm{A}$ is used here (the same for later ".B" and ".C"). Standard errors are reported in parentheses, allowing for arbitrary clustering across journals and years. ${ }^{* * *} \mathrm{p}<0.01,{ }^{* *} \mathrm{p}<0.05,{ }^{*} \mathrm{p}<0.1$. 
different between general-interest journals and field journals. That is, speaking of equation (14), $\tau_{\omega}=\tau$ is suggested by the data.

Notice that there are in total four interaction terms here, three two-way interactions (labeled I, II, and III in Table 5) and one three-way interaction (labeled IV in Table 5). A possible concern arises as to whether the heavy non-linearity introduced by them into the regression deprives the statistical significance of the three-way interaction term. This concern is legitimate, since the coefficient of the two-way interaction term $T_{t} \cdot G_{i}$, which is statistically significant in the previous Table 4, now loses statistical significance. To address the concern, we conduct joint-significance tests on three different combinations of coefficients: II+III, I+IV, and all-four.

We reach two findings from the joint-significance tests. One, the all-four combination shows clear joint significance ( $\mathrm{p}$-value: 0.001 or less). Two, the all-four joint significance is mainly driven by the joint significance of combination II+III rather than that of I+IV. These two findings corroborate the conclusion we drew above. That is, the role of ranking value in determining the trend is no different between general-interest journals and field journals. They also corroborate our findings from Table 4 by demonstrating that the significance of two-way interactions $T_{t} \cdot G_{i}$ and $T_{t} \cdot R_{i}$ (i.e., combination II+III here) is not caused by mis-specified functional forms.

\subsection{Robustness}

We check the robustness of the results in Table 4 in three ways. The first check is on the estimation method. The dependent variable $S_{i t}$, as a share variable, has a data range between 0 and 1 . The previous Table 4 uses linear regressions, which do not econometrically constrain the range of the dependent variable. We experiment with the fractional logit estimation that constrains the dependent variable between 0 and 1 . The results are reported in Table $\mathbf{6}$, where marginal effects (calculated at the means of all regressors) are reported. The estimated signs are the same as in Table 4, while the estimated magnitudes are quite similar to those in Table 4. The drawback of the fractional logit estimation is that, given its non-linear functional forms, the choice of regressor

values in the marginal-effect calculation is largely arbitrary. Thus, we use it only as a robustness check.

The next robustness check focuses on the ranking values, and its results are reported in Table 7. In columns (1)-(4) of the table, the regressions in Table 4 are rerun with top- 5 journals excluded from the sample. This is to address the fact that top- 5 journals, which are general-interest journals, have the best rankings (i.e., the smallest ranking values $R_{i}$ ) among all economics journals. As a result, when $R_{i}$ takes on these smallest values, it has a mechanical correlation with $G_{i}$. This causes a potential "top-general-interest journal effect" that may hide behind the estimates in Table 4 . It is no longer an issue when top-5 journals are excluded. As shown in columns (1)-(4), the findings from Table 4 remain. 
Table 6: Robustness I: Fractional Logit Model

\begin{tabular}{|c|c|c|c|c|}
\hline $\begin{array}{l}\text { Dep. Variable: average page share within } \\
\text { journal-year duplets }\end{array}$ & (1) & $(2)$ & (3) & (4) \\
\hline \multirow[t]{2}{*}{ General-interest dummy } & $-0.00765^{* *}$ & $-0.01160^{* *}$ & $-0.01237^{* *}$ & $-0.01344^{* *}$ \\
\hline & $(0.00079)$ & $(0.00107)$ & $(0.00122)$ & $(0.00144)$ \\
\hline \multirow[t]{2}{*}{ Ranking value§ } & $0.01690^{* *}$ & $0.02386^{* *}$ & $0.02533^{* *}$ & $0.02786^{* *}$ \\
\hline & $(0.00271)$ & $(0.00329)$ & $(0.00359)$ & $(0.00402)$ \\
\hline \multirow{2}{*}{ Time index A } & $-0.00020^{* *}$ & -0.00012 & & \\
\hline & $(0.00006)$ & $(0.00009)$ & & \\
\hline \multirow[t]{2}{*}{ Time index A $\times$ General-interest dummy } & & $0.00040^{* *}$ & & \\
\hline & & $(0.00010)$ & & \\
\hline \multirow[t]{2}{*}{ Time index $\mathrm{A} \times$ Ranking value } & & $-0.00071^{* *}$ & & \\
\hline & & $(0.00023)$ & & \\
\hline \multirow[t]{2}{*}{ Time index B } & & & -0.00035 & \\
\hline & & & $(0.00029)$ & \\
\hline \multirow[t]{2}{*}{ Time index $\mathrm{B} \times$ General-interest dummy } & & & $0.00119^{* *}$ & \\
\hline & & & $(0.00029)$ & \\
\hline \multirow[t]{2}{*}{ Time index $\mathrm{B} \times$ Ranking value } & & & $-0.00214^{* *}$ & \\
\hline & & & $(0.00070)$ & \\
\hline \multirow[t]{2}{*}{ Time index C } & & & & -0.00078 \\
\hline & & & & $(0.00071)$ \\
\hline \multirow[t]{2}{*}{ Time index $\mathrm{C} \times$ General-interest dummy } & & & & $0.00291^{* *}$ \\
\hline & & & & $(0.00072)$ \\
\hline \multirow[t]{2}{*}{ Time index $\mathrm{C} \times$ Ranking value } & & & & $-0.00555^{* *}$ \\
\hline & & & & $(0.00172)$ \\
\hline \multirow[t]{2}{*}{ Fee } & $0.00229^{* *}$ & $0.00229^{* *}$ & $0.00229^{* *}$ & $0.00229^{* *}$ \\
\hline & $(0.00047)$ & $(0.00047)$ & $(0.00047)$ & $(0.00047)$ \\
\hline Publisher fixed effects & $\mathrm{Y}$ & $\mathrm{Y}$ & $\mathrm{Y}$ & $\mathrm{Y}$ \\
\hline Observations & 831 & 831 & 831 & 831 \\
\hline
\end{tabular}

$\S$ A larger ranking value means a weaker ranking. Standard errors in parentheses. ${ }^{*} \mathrm{p}<0.05,{ }^{* *} \mathrm{p}<0.01$.

In columns (5)-(8) of Table 7, the ranking values are from the journal rankings compiled by the Kiel Institute. The $\mathrm{A}+, \mathrm{A}$, and $\mathrm{B}+$ journals rated by the Kiel Institute are coded as ranking values $0,0.5$, and 1 , respectively. Having only three levels in the ranking value reduces the variations in $R_{i}$. The coefficient of its interaction with the time index, namely $\hat{\delta}_{R}$, is now negative but statistically insignificant. However, the coefficient of the ranking value itself, namely $\hat{\theta}_{R}$, remains positive and statistically significant as before (the significance level actually rises a bit). The results related to journal type $G_{i}$, either interacted or not, also remain as before.

The last robustness check is concerned with the potential differences between pure-economics journals and b-school journals. In Table 8, columns (1)-(3) correspond to pure-economics journals, while columns (4)-(6) correspond to b-school journals. Since b-school journals are all field journals, 
Table 7: Robustness II: Alternative Rankings

\begin{tabular}{|c|c|c|c|c|c|c|c|c|}
\hline & $(1)$ & $(2)$ & $(3)$ & $(4)$ & $(5)$ & $(6)$ & $(7)$ & $(8)$ \\
\hline Sample: & \multicolumn{4}{|c|}{ Non-top-5 Journals } & \multicolumn{4}{|c|}{ Full } \\
\hline Ranking: & \multicolumn{4}{|c|}{ Benchmark } & \multicolumn{4}{|c|}{ Kiel } \\
\hline General-interest dummy & $\begin{array}{c}-0.00596^{*} \\
(0.00358)\end{array}$ & $\begin{array}{c}-0.00974^{* *} \\
(0.00378)\end{array}$ & $\begin{array}{c}-0.0105^{* * *} \\
(0.00390)\end{array}$ & $\begin{array}{c}-0.0117^{* * *} \\
(0.00393)\end{array}$ & $\begin{array}{l}-0.00543^{*} \\
(0.00299)\end{array}$ & $\begin{array}{c}-0.00918^{* * *} \\
(0.00310)\end{array}$ & $\begin{array}{c}-0.00990^{* * *} \\
(0.00327)\end{array}$ & $\begin{array}{c}-0.0109^{* * *} \\
(0.00340)\end{array}$ \\
\hline Ranking value§ & $\begin{array}{c}0.0144 \\
(0.0153) \\
\end{array}$ & $\begin{array}{c}0.0242 \\
(0.0149) \\
\end{array}$ & $\begin{array}{c}0.0262^{*} \\
(0.0150) \\
\end{array}$ & $\begin{array}{c}0.0299^{* *} \\
(0.0150)\end{array}$ & $\begin{array}{c}0.0109^{* * *} \\
(0.00294)\end{array}$ & $\begin{array}{c}0.0125^{* * *} \\
(0.00332)\end{array}$ & $\begin{array}{c}0.0128^{* * *} \\
(0.00347)\end{array}$ & $\begin{array}{c}0.0131^{* * *} \\
(0.00361)\end{array}$ \\
\hline Time index A & $\begin{array}{c}0.000279^{* * \text { * }} \\
(9.45 \mathrm{e}-05)\end{array}$ & $\begin{array}{l}-0.000108 \\
(0.000173)\end{array}$ & & & $\begin{array}{c}-0.000223^{* *} \\
(8.85 \mathrm{e}-05)\end{array}$ & $\begin{array}{l}-0.000237 \\
(0.000207)\end{array}$ & & \\
\hline Time index $\mathrm{A} \times$ General-interest dummy & & $\begin{array}{r}0.000377^{* *} \\
(0.000126)\end{array}$ & & & & $\begin{array}{c}0.000371^{* *} \\
(0.000170)\end{array}$ & & \\
\hline Time index $\mathrm{A} \times$ Ranking value & & $\begin{array}{r}-0.000979^{* *} \\
(0.000497)\end{array}$ & & & & $\begin{array}{l}-0.000166 \\
(0.000186)\end{array}$ & & \\
\hline Time index B & & & $\begin{array}{l}-0.000314 \\
(0.000512)\end{array}$ & & & & $\begin{array}{l}-0.000719 \\
(0.000568)\end{array}$ & \\
\hline Time index $\mathrm{B} \times$ General-interest dummy & & & $\begin{array}{c}0.00112^{* * *} \\
(0.000374)\end{array}$ & & & & $\begin{array}{l}0.00111^{* *} \\
(0.000494)\end{array}$ & \\
\hline Time index $B \times$ Ranking value & & & $\begin{array}{c}-0.00294^{* *} \\
(0.00145)\end{array}$ & & & & $\begin{array}{l}-0.000475 \\
(0.000512)\end{array}$ & \\
\hline Time index C & & & & $\begin{array}{c}-0.000649 \\
(0.00119)\end{array}$ & & & & $\begin{array}{l}-0.00176 \\
(0.00129)\end{array}$ \\
\hline Time index $\mathrm{C} \times$ General-interest dummy & & & & $\begin{array}{c}0.00286^{* * *} \\
(0.000786)\end{array}$ & & & & $\begin{array}{c}0.00273^{* *} \\
(0.00112)\end{array}$ \\
\hline Time index $\mathrm{C} \times$ Ranking value & & & & $\begin{array}{c}-0.00772^{* *} \\
(0.00321)\end{array}$ & & & & $\begin{array}{l}-0.00114 \\
(0.00112)\end{array}$ \\
\hline Fee & $\begin{array}{c}0.00184 \\
(0.00169) \\
\end{array}$ & $\begin{array}{c}0.00184 \\
(0.00169) \\
\end{array}$ & $\begin{array}{c}0.00184 \\
(0.00169) \\
\end{array}$ & $\begin{array}{c}0.00185 \\
(0.00168) \\
\end{array}$ & $\begin{array}{c}0.00257 \\
(0.00165) \\
\end{array}$ & $\begin{array}{c}0.00255 \\
(0.00166) \\
\end{array}$ & $\begin{array}{c}0.00255 \\
(0.00166) \\
\end{array}$ & $\begin{array}{c}0.00255 \\
(0.00166) \\
\end{array}$ \\
\hline Publisher fixed effects & $\mathrm{Y}$ & $\mathrm{Y}$ & $\mathrm{Y}$ & $\mathrm{Y}$ & $\mathrm{Y}$ & $\mathrm{Y}$ & $\mathrm{Y}$ & $\mathrm{Y}$ \\
\hline Observations & 726 & 726 & 726 & 726 & 831 & 831 & 831 & 831 \\
\hline R-squared & 0.581 & 0.591 & 0.590 & 0.591 & 0.594 & 0.602 & 0.601 & 0.601 \\
\hline
\end{tabular}

§ A larger ranking value means a weaker ranking. Standard errors are reported in parentheses, allowing for arbitrary clustering across journals and years. $* * * \mathrm{p}<0.01, * * \mathrm{p}<0.05, * \mathrm{p}<0.1$.

we cannot include $G_{i}$ in the regressions. The comparison is now mainly in the interaction between $R_{i}$ and $T_{t}$. The earlier findings turn out to hold for both journal groups, and no difference is found between the two groups.

\subsection{Page Limits and Field-specific Specialization}

The linchpin of the model in Section 2 is the expertise loss rate $\gamma$ within a journal's scope. In the above empirical study, $\gamma$ is linked to journal type $\left(G\right.$ or $F$ ) and ranking value $R_{i}$ through equation (5). Below, we examine two other journal characteristics related to $\gamma$. 
Table 8: Robustness III: Pure-economics Journals vs. B-school Journals

$\begin{array}{llll}(1) & (2) & (3) & (5)\end{array}$

$(5)$

Dep. Variable: average page share within journal-year duplets

\begin{tabular}{|c|c|c|c|c|c|c|}
\hline \multirow[b]{2}{*}{ Ranking number§ } & \multicolumn{3}{|c|}{ Pure-economics journal } & \multicolumn{3}{|c|}{ B-school Journals } \\
\hline & $\begin{array}{c}0.0255^{* *} \\
(0.0125) \\
\end{array}$ & $\begin{array}{c}0.0273^{* *} \\
(0.0127) \\
\end{array}$ & $\begin{array}{c}0.0309 * * \\
(0.0129) \\
\end{array}$ & $\begin{array}{c}0.0642^{* * * *} \\
(0.00577) \\
\end{array}$ & $\begin{array}{c}0.0660^{* * *} \\
(0.00653) \\
\end{array}$ & $\begin{array}{c}0.0690 * * * \\
(0.00689) \\
\end{array}$ \\
\hline Time index A & $\begin{array}{c}8.77 \mathrm{e}-05 \\
(0.000129)\end{array}$ & & & $\begin{array}{c}-0.000673^{*} \\
(0.000406)\end{array}$ & & \\
\hline Time index $\mathrm{A} \times$ Ranking value & $\begin{array}{c}-0.000903^{* *} \\
(0.000411)\end{array}$ & & & $\begin{array}{c}-0.000967^{* *} \\
(0.000456)\end{array}$ & & \\
\hline Time index B & & $\begin{array}{c}0.000273 \\
(0.000380)\end{array}$ & & & $\begin{array}{c}-0.00204^{*} \\
(0.00116)\end{array}$ & \\
\hline Time index $\mathrm{B} \times$ Ranking value & & $\begin{array}{c}-0.00272^{* *} \\
(0.00116)\end{array}$ & & & $\begin{array}{c}-0.00287^{* *} \\
(0.00131)\end{array}$ & \\
\hline Time index $\mathrm{C}$ & & & $\begin{array}{c}0.000743 \\
(0.000897)\end{array}$ & & & $\begin{array}{l}-0.00464 \\
(0.00297)\end{array}$ \\
\hline Time index $\mathrm{C} \times$ Ranking value & & & $\begin{array}{c}-0.00725^{* * *} \\
(0.00248)\end{array}$ & & & $\begin{array}{c}-0.00723^{* *} \\
(0.00334)\end{array}$ \\
\hline Fee & $\begin{array}{r}-0.000704 \\
(0.00175) \\
\end{array}$ & $\begin{array}{r}-0.000704 \\
(0.00175) \\
\end{array}$ & $\begin{array}{r}-0.000703 \\
(0.00177) \\
\end{array}$ & $\begin{array}{c}0.00970 * * * \\
(0.000438) \\
\end{array}$ & $\begin{array}{c}0.00970 * * * \\
(0.000474)\end{array}$ & $\begin{array}{c}0.00970^{* * *} \\
(0.000320) \\
\end{array}$ \\
\hline Publisher fixed effects & $\mathrm{Y}$ & $\mathrm{Y}$ & $\mathrm{Y}$ & $\mathrm{Y}$ & $\mathrm{Y}$ & $\mathrm{Y}$ \\
\hline Observations & 726 & 726 & 726 & 105 & 105 & 105 \\
\hline R-squared & 0.593 & 0.592 & 0.593 & 0.659 & 0.657 & 0.643 \\
\hline
\end{tabular}

$\S$ A larger ranking value means a weaker ranking. Standard errors are reported in parentheses, allowing for arbitrary clustering across journals and years. ${ }^{* * *} \mathrm{p}<0.01,{ }^{* *} \mathrm{p}<0.05,{ }^{*} \mathrm{p}<0.1$.

Page Limits on Initial Submissions Some journals impose page limits on initial submissions, which indirectly reflect an expertise cost concern: longer submissions do not contribute proportionally more insights (recall Dixit's example in the introduction). As found by Card and DellaVigna (2014), setting page limits on initial submissions risks losing high-quality but long submissions. Their reasoning is that shortening an article incurs a cost for authors, so that only authors that have no better alternative outlets choose to observe the limits and shorten their submissions. This reflects the "revealed preferences" of authors. Following their reasoning, journals would not impose page limits on initial submissions unless they believed that expertise costs were a significant concern for them, because imposing page limits risks losing high-quality, long submissions. Thus, we hypothesize that the earlier results related to $G_{i}, R_{i}$, or both will become weaker for journals that do not impose page limits.

For journals that impose page limits on initial submissions, the earlier results are expected to remain. The page limits on initial submissions would not exhaust the variations in $S_{i t}$ for two reasons. First, page limits are not always binding. Submissions that are initially shorter than the page limits are unaffected by the page limits. Second, page limits are different across journals. ${ }^{20}$

\footnotetext{
${ }^{20}$ We observe only the current page limits (if applicable) imposed by journals. They are found in journals' guidelines for authors. It would be nice if the page limit could be tracked over time for each journal, similar to what Card and
} 
We divide journals into two groups according to whether they impose page limits on initial submissions, and rerun regression (11) using each of the two groups. The results are reported in Table 9. Columns (1)-(4) in the table, which correspond to journals with page limits, show results that resemble the earlier ones. The results in columns (5)-(8) correspond to journals without page limits, where the coefficient of the interaction between $G_{i}$ and $T_{t}$ remains as before, but the coefficient of the interaction between $R_{i}$ and $T_{t}$ becomes statistically insignificant. This weaker pattern is consistent with the revealed preferences that we expect. It also indicates that journals' perception of expertise loss differs mainly by journal rankings rather than between journal types ( $G$ or $F$ ) - among journals that do not impose page limits, field journals have a sharper shrinkage in $S_{i t}$.

Field-specific Specialization Ellison (2002a) reports (in its Table 9) a specialization index for seven fields of economics in the 1990s. ${ }^{21}$ We run regression (11), with $G_{i}$ replaced by the Ellison specialization index, and with a sample that includes only field journals corresponding to the seven fields. We hypothesize that a higher specialization level is associated with a smaller $\gamma$, so that field journals corresponding to more specialized fields have a sharper decrease in $S_{i}$. The results are reported in Table 10. The journals in more specialized fields display a sharper decrease in $S_{i t}$. The results related to the ranking value $R_{i}$ remain the same as before.

It should be noted that the more specialized fields may also have a tendency that raises rather than reduces $\gamma$. That is, research questions could be more likely to fall into the specialized domains of the corresponding researchers, which raises the probability of overstretching expertise. We cannot rule out this possibility. But this possibility works against finding results that support our speculation — without this opposing effect, the page-share shrinking in more specialized fields would be even sharper. In this regard, our findings in Table 10 should be interpreted as a net effect.

It should also be noted that the Ellison specialization index, despite being a field-specific measure, was constructed using publications in top-5 journals. In contrast, the sample used in Table 10 includes only field journals. On the one hand, this is a measurement issue in our context, because the specialization level in a field's top-5 journal publications is not equivalent to that field's specialization level in field journals. On the other, this is a strength of the index in our context, because it means that the specialization index constructed for those fields has no direct correlation with the $S_{i t}$ of field journals. If the specialization index were constructed using field journals, we would have to worry about whether those prolific authors of the field journals directly impact the

DellaVigna (2014) did for AER and JEEA. However, in our context, there is no way to track page limits except to interview a journal's every on-duty editor during the sample period.

${ }^{21}$ The specialization index was constructed in the following way: treat JEL codes as subfields into which the field is divided, and compute Ellison-Glaeser indices on the set of economists who have two or more publications in the top-5 journals in the field. Every Ellison-Glaeser index is an adjusted concentration measure that compares those authors' publication distribution across subfields with the distribution of all publications across subfields. Ellison (2002a) restricted the analysis to seven fields for which the relevant sample of economists exceeded 10 in the 1990 s and for which the JEL codes provide a reasonably fine field division. The seven fields are microeconomic theory, macroeconomics, labor economics, industrial organization, international economics, public finance, and finance. 
$S_{i t}$ of those journals.

\section{Concluding Remarks}

We find economics journals to be a good subject for studying the economics of economics. Journals produce articles, sell them and produce a profit. Economists are largely employed by journals, because publishing in journals is essential to a career in this profession, directly determining one's salary, promotion, reputation, funding, and what (and how much) to teach. Most importantly, recent economic knowledge has been provided mainly in the form of journal articles. Journals are economic goods. By analyzing journals, the production of economics can be rationalized using existing economic models, without resort to a separate economic model specifically built for economics.

We borrow a monopolistic competition model from the literature to model the behavior of economics journals, and use data from 41 journals over the last two decades to test the model. Every journal covers a range of topics and decides its length and number of articles to publish. Every new article incurs a fixed cost, but using longer articles to cover more topics incurs increasing expertise cost. As a tradeoff, journals divide their length among a limited number of articles with limited length. The rise of the World Wide Web and online search engines in the last two decades were a negative shock to readers' attention on journal issues and their willingness to pay. The model predicts that journals will produce longer journals and more articles, but as a net effect, the page share of an average article in a journal shrinks over time. This prediction receives support from the data. Moreover, as predicted, general-interest journals and better ranked journals, where expertise costs rise faster across topics within a journal, turn out to shrink less. This unique prediction is also supported by the data.

A limitation of this study is that the expertise of authors is treated simply as a production factor. In our model, journals may let researchers who have less relevant expertise write on a topic, as long as journals would like to pay a higher "expertise cost." Put differently, paying a higher expertise cost can substitute the relevant expertise, just like employing more labor to compensate for lower labor productivity. Using experts to replace the objectified expertise here will enable one to model a real matching mechanism between experts and topics within a journal. Such a model may also be empirically testable, if authors in the journal data are linked to their research profiles (such as online vitae). 
Table 9: Page Limits on Initial Submissions

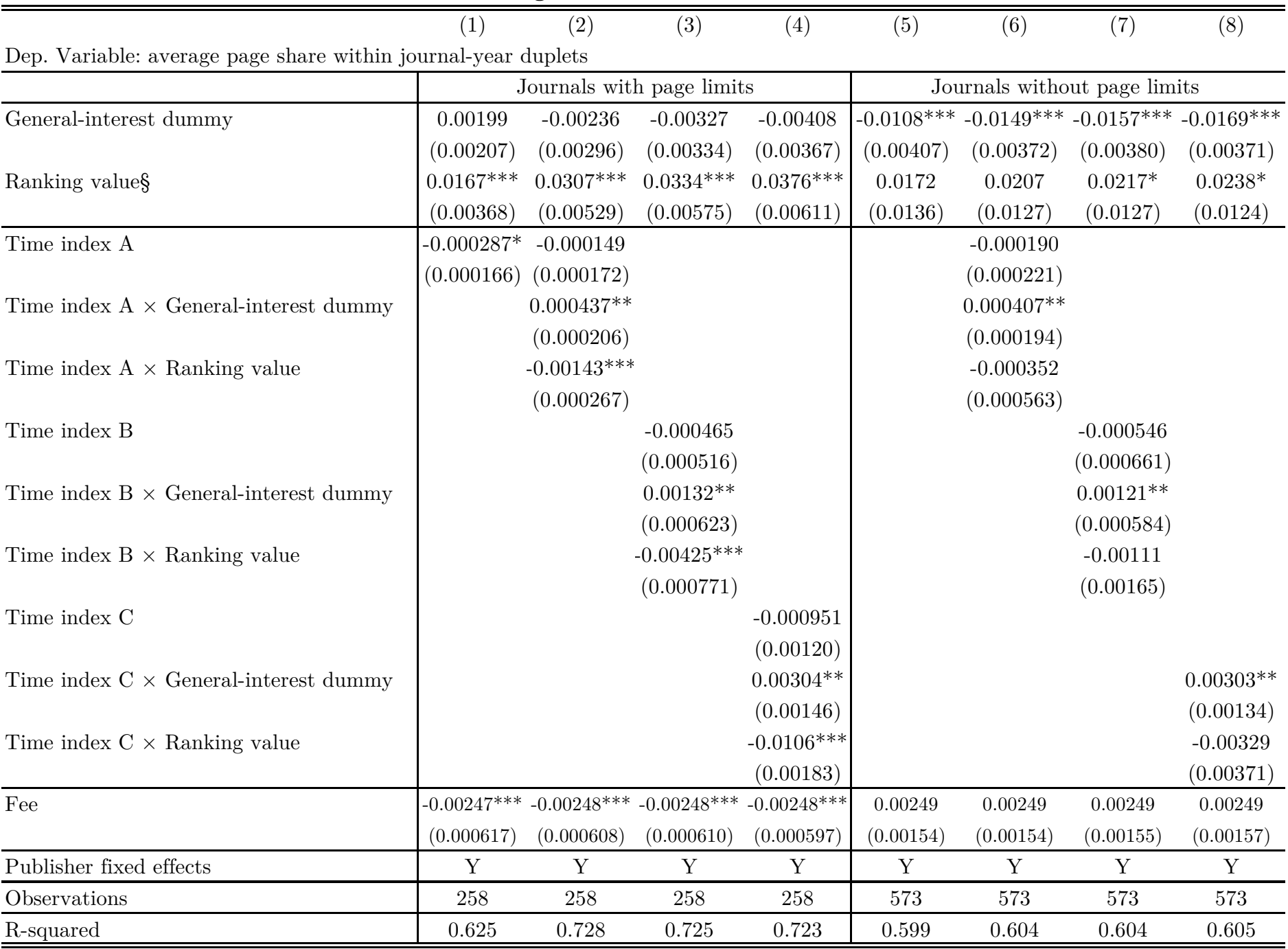

§ A larger ranking value means a weaker ranking. Standard errors are reported in parentheses, allowing for arbitrary multi-way clustering across journals and years. $* * * \mathrm{p}<0.01,{ }^{* *} \mathrm{p}<0.05,{ }^{*} \mathrm{p}<0.1$. 
Table 10: Field-specific Specialization

\begin{tabular}{|c|c|c|c|c|}
\hline \multicolumn{5}{|c|}{ Dep. Variable: average wage share within journal-year duplets } \\
\hline & $(1)$ & $(2)$ & $(3)$ & $(4)$ \\
\hline \multirow[t]{2}{*}{ Ellison specialization index } & $-0.0769^{* * *}$ & $-0.0434^{* *}$ & $-0.0365^{*}$ & -0.0302 \\
\hline & $(0.0218)$ & $(0.0203)$ & $(0.0204)$ & $(0.0218)$ \\
\hline \multirow[t]{2}{*}{ Ranking value§ } & 0.0311 & $0.0407^{*}$ & $0.0425^{* *}$ & $0.0459^{* *}$ \\
\hline & $(0.0214)$ & $(0.0212)$ & $(0.0212)$ & $(0.0213)$ \\
\hline \multirow[t]{2}{*}{ Time index A } & $-0.000372^{* *}$ & $0.000761^{* * *}$ & & \\
\hline & $(0.000156)$ & $(0.000280)$ & & \\
\hline \multirow[t]{2}{*}{ Time index $\mathrm{A} \times$ Ellison specialization index } & & $-0.00335^{* * *}$ & & \\
\hline & & $(0.000897)$ & & \\
\hline \multirow[t]{2}{*}{ Time index $\mathrm{A} \times$ Ranking value } & & $-0.000926^{* *}$ & & \\
\hline & & $(0.000372)$ & & \\
\hline \multirow[t]{2}{*}{ Time index B } & & & $0.00230^{* * *}$ & \\
\hline & & & $(0.000793)$ & \\
\hline \multirow[t]{2}{*}{ Time index $\mathrm{B} \times$ Ellison specialization index } & & & $-0.0101^{* * *}$ & \\
\hline & & & $(0.00255)$ & \\
\hline \multirow[t]{2}{*}{ Time index $\mathrm{B} \times$ Ranking value } & & & $-0.00276^{* * *}$ & \\
\hline & & & $(0.00106)$ & \\
\hline \multirow[t]{2}{*}{ Time index $\mathrm{C}$} & & & & $0.00544^{* * *}$ \\
\hline & & & & $(0.00179)$ \\
\hline \multirow[t]{2}{*}{ Time index $\mathrm{C} \times$ Ellison specialization index } & & & & $-0.0233^{* * *}$ \\
\hline & & & & $(0.00643)$ \\
\hline \multirow[t]{2}{*}{ Time index $\mathrm{C} \times$ Ranking value } & & & & $-0.00726^{* * *}$ \\
\hline & & & & $(0.00255)$ \\
\hline \multirow[t]{2}{*}{$\overline{\text { Fee }}$} & $0.00597^{* * *}$ & $0.00597^{* * *}$ & $0.00597^{* * *}$ & $0.00597^{* * *}$ \\
\hline & $(0.00200)$ & $(0.00199)$ & $(0.00199)$ & $(0.00199)$ \\
\hline Publisher fixed effects & $\mathrm{Y}$ & $\mathrm{Y}$ & $\mathrm{Y}$ & $\mathrm{Y}$ \\
\hline Observations & 502 & 502 & 502 & 502 \\
\hline R-squared & 0.654 & 0.680 & 0.679 & 0.677 \\
\hline
\end{tabular}

$\S$ A larger ranking value means a weaker ranking. General interests journals are excluded. Standard errors are reported in parentheses, allowing for arbitrary clustering across journals and years. $* * * \mathrm{p}<0.01, * *$ $\mathrm{p}<0.05, * \mathrm{p}<0.1$. 


\section{References}

Azar, Ofer H. (2007), "The Slowdown In First-Response Times Of Economics Journals: Can It Be Beneficial?" Economic Inquiry, 45, 179-187.

Becker, Gary S. and Kevin M. Murphy (1992), "The division of labor, coordination costs, and knowledge." Quarterly Journal of Economics, 107, 1137-1160.

Brogaard, Jonathan, Joseph Engelberg, and Christopher A. Parsons (2014), "Networks and productivity: Causal evidence from editor rotations." Journal of Financial Economics, 111, 251-270.

Cameron, A. Colin, Jonah B. Gelbach, and Douglas L. Miller (2011), "Robust Inference With Multiway Clustering." Journal of Business $\&$ Economic Statistics, 29, 238-249.

Card, David and Stefano DellaVigna (2014), "Page limits on economics articles: Evidence from two journals." Journal of Economic Perspectives, 28, 149-168.

Chaney, Thomas and Ralph Ossa (2013), "Market size, division of labor, and firm productivity." Journal of International Economics, 90, 177-180.

Cherkashin, Ivan, Svetlana Demidova, Susumu Imai, and Kala Krishna (2009), "The inside scoop: acceptance and rejection at the Journal of International Economics." Journal of International Economics, 77, 120-132.

Dixit, Avinash (1998), "My system of work (not!)." In Passion and Craft (Michael Szenberg, ed.), University of Michigan Press.

Edlin, Aaron S. and Daniel L. Rubinfeld (2005), "The bundling of academic journals." American Economic Review, 95, 441-446.

Einav, Liran and Leeat Yariv (2006), "What's in a surname? the effects of surname initials on academic success." Journal of Economic Perspectives, 20, 175-188.

Ellison, Glenn (2002a), "The Slowdown of the Economics Publishing Process." Journal of Political Economy, 110, 947-993.

Ellison, Glenn (2002b), "Evolving Standards for Academic Publishing: A q-r Theory." Journal of Economic Perspectives, 110, 994-1034.

Engemann, Kristie M. and Howard J. Wall (2009), "A journal ranking for the ambitious economist." Federal Reserve Bank of St. Louis Review, 91, 127-39.

Feenberg, Daniel R., Ina Ganguli, Patrick Gaule, and Jonathan Gruber (2015), "It's Good to be First: Order Bias in Reading and Citing NBER Working Papers." NBER Working Paper 21141.

Friberg, Richard (2014), "The Wish List of an Editor: Some Reflections on Editing the Scandinavian Journal of Economics." In Secrets of Economics (Michael Szenberg and Lall Ramrattan, eds.), 45-52, The MIT Press. 
Garicano, Luis and Thomas N. Hubbard (2003), "Specialization, firms, and markets: The division of labor within and between law firms." NBER Working Paper No. 9719.

Haeussler, Carolin and Henry Sauermann (2016), "The Division of Labor in Teams: A Conceptual Framework and Application to Collaborations in Science." NBER Working Paper No. 22241.

Hamermesh, Daniel S. (2013), "Six Decades of Top Economics: Publishing: Who and How?" Journal of Economic Literature, 51, 162172.

Head, Keith, Yao Amber Li, and Asier Minondox (2015), "Geography, ties, and knowledge flows: Evidence from citations in mathematics." Working paper.

Huang, Wei (2014), "Do ABCs Get More Citations Than XYZs?" Economic Inquiry, 53, 773-789.

Jeon, Doh-Shin and Jean-Charles Rochet (2010), "The pricing of academic journals: A two-sided market perspective." American Economic Journal: Microeconomics, 2, 222-255.

Laband, David N. and Robert D. Tollison (2000), "Intellectual Collaboration." Journal of Political Economy, 108, 632-661.

Leslie, Derek (2005), "Are delays in academic publishing necessary?" American Economic Review, 95, 407413.

Nevo, Aviv, Daniel L. Rubinfeld, and Mark McCabe (2005), "Academic journal pricing and the demand of libraries." American Economic Review Papers and Proceedings, 95, 447-452.

Ray, Debraj and Arthur Robson (2016), "Certified random: A new order for co-authorship." NBER Working Paper No. 22602.

Rosenblat, Tanya S. and Markus M. Mobius (2004), "Getting closer or drifting apart." Quarterly Journal of Economics, 119, 971-1009.

Smith, Adam (1776), The Wealth of Nations. CreateSpace Independent Publishing Platform (2016).

Stigler, George J. (1951), "The division of labor is limited by the extent of the market." Journal of Political Economy, 59, 185-193.

van Praag, C. Mirjam and Bernard M. S. van Praag (2008), "The Benefits of Being Economics Professor A (Rather than Z)." Economica, 75, 782-796.

Welch, Ivo (2014), "Referee recommendations." Review of Financial Studies, 27, 2773-2804.

Yang, Xiaokai (2001), Economics: New Classical versus Neoclassical Frameworks. Blackwell Publishers.

Young, Allyn (1928), "Increasing returns and economic progress." Economic Journal, 38, 527-542. 
Zilibotti, Fabrizio (2014), "Memoirs of an editor." In Secrets of Economics Editors (Michael Szenberg and Lall Ramrattan, eds.), 97-118, The MIT Press.

\section{Appendix: Published entries that are excluded}

Not all entries published in a journal are considered to be articles. Entries with the following terms in their titles are excluded: errata (erratum), corrigendum (corrigenda, correction), in memory (in memoriam, memories), editorial, report, minutes, advertisement, correspondence, symposium (overview, introduction of symposium, special issue, roundtable), prize, statement, addendum, acknowledgement, index, preface, contribution, presidential speech (and the like), medal (medalist), questionnaire, book review, meeting (society, association, NSF), reviewer list (and the like), retraction, obituary, anniversary, lecture, celebration, proposals, eulogy, version, and calls for. Journals may also have customized entries that belong to this category, such as "focus on authors" in Marketing Science.

It is important to note that the above terms in titles, if referring to specific economic concepts, are exceptions. For example, "correction" in the title of an econometric article on error correction models. Another example is "award" in the title of a micro-theory article on optimal awards .

A subtler case is the entries with the following terms in their titles: discussion, reply, response, comment, commentary, rejoin, problems, solution(s), and controversy. On the one hand, such entries, as derivatives of other existing articles, do not make independent contributions. On the other, many of them point out nontrivial mistakes, show new results, or make standalone empirical findings, which should not be excluded. As a compromise, we keep those longer than five pages and consider them as equivalents to articles, and exclude the rest. ${ }^{22}$

\footnotetext{
${ }^{22}$ If we exclude all comment-type entries, the 5 th percentile of article length in the remaining sample is five pages. In other words, our "five-page rule" keeps comment-type entries that are longer than 1/20 of the narrowly defined original articles. This is a conservative criterion. In addition, excluding too many entries would reduce the accuracy of page-share calculation.
} 
Table A1: List of Journals

\begin{tabular}{|c|c|}
\hline Journal name & Number of years available \\
\hline American Economic Journal: Applied Econ* & 6 \\
\hline American Economic Review & 21 \\
\hline Econometric Theory & 21 \\
\hline Econometrica & 21 \\
\hline Economic Journal & 21 \\
\hline European Economic Review & 21 \\
\hline Games \& Economic Behavior & 21 \\
\hline International Economic Review & 21 \\
\hline Journal of Accounting \& Economics & 21 \\
\hline Journal of Applied Econometrics & 21 \\
\hline Journal of Banking \& Finance & 21 \\
\hline Journal of Development Economics & 21 \\
\hline Journal of Econometrics & 21 \\
\hline Journal of Economic Behavior \& Org & 21 \\
\hline Journal of Economic Growth** & 19 \\
\hline Journal of Economic Theory & 21 \\
\hline Journal of Finance & 21 \\
\hline Journal of Financial Economics & 21 \\
\hline Journal of Human Resources & 21 \\
\hline Journal of Industrial Economics & 21 \\
\hline Journal of International Economics & 21 \\
\hline Journal of Labor Economics & 21 \\
\hline Journal of Law \& Economics & 21 \\
\hline Journal of Law, Economics \& Organization & 21 \\
\hline Journal of Monetary Economics & 21 \\
\hline Journal of Money Credit \& Banking & 21 \\
\hline Journal of Political Economy & 21 \\
\hline Journal of Public Economics & 21 \\
\hline Journal of Risk \& Uncertainty & 21 \\
\hline Journal of Urban Economics & 21 \\
\hline Journal of the European Econ Association*** & 12 \\
\hline Marketing Science & 21 \\
\hline Oxford Economic Paper & 21 \\
\hline Quarterly Journal of Economics & 21 \\
\hline Rand Journal of Economics & 21 \\
\hline Review of Economic Dynamics**** & 17 \\
\hline Review of Economic Studies & 21 \\
\hline Review of Economics \& Statistics & 21 \\
\hline Review of Financial Studies & 21 \\
\hline Scandinavian Journal of Economics & 21 \\
\hline World Development & 21 \\
\hline Total & 831 \\
\hline
\end{tabular}

Notes: The starting year of the journal: * 2009, ** 1996, *** 2003, **** 1998. 